\title{
Swift Five Force LRP Data Process Algorithm Machine Learning Ai Data Process
}

\author{
Kranthi Lammatha, Karthikeyan Chinnusamy, \\ Naresh Reddy Malgireddy
}

\begin{abstract}
One of the main challenges of online stores is providing the right product to the customers, instead of showing all the products where the customer lost in the maze of the products to find the right products due to that customer loose the interest and leave the website, Instead of selling anything and everything where the customer distracted, Swift is mobile app specialize to sell and buy only shoes. It helps customer to discover shoes they'll love and offers them ways to easily and intuitively pick the product that's right for them. It involves just the buyer and seller who can interact through a single platform SWIFT for purchasing and selling SHOES. Style studio this feature is to guide the user through their purchase experience and enable them to virtually try before they buy.
\end{abstract}

Keywords--- Swift app, Style Studio, SEO, Recommendation.

\section{INTRODUCTION}

"An expert is someone who has succeeded in making decisions and judgments simpler through knowing what to pay attention to and what to ignore." Edward de Bono

Since the birth of intelligent man, he has continually strive to organize his thoughts, his resources and most importantly, his fellow men. In the modern age, when our resources are rapidly being depleted and the global economic condition is looking bleak, it has become a necessity to better plan every little step and tackle the little problems which will eventually form pieces of the giant invisible jigsaw puzzle. At this critical juncture the need for engineers to propel the economy to new heights from the slow recuperation it is currently undergoing has become ever more unequivocal. Only an amalgamation of best management practices, superior engineering and impeccable leadership, the primary reason for us to develop this App Swift.

Our project is to set a trend. Instead of selling anything and everything, we specialize in only one product; selling shoes. All that is required is to download the app and place the order according to the customer's needs and provide the best user experience.

We created a single platform form end users point of view such as shoes. This is the product that has the power to capture the market and encapsulate the minds of the customers.

The present pattern is to put everything in one. All in one to be precise, which is what most of the E-commerce giants are doing. The chaos and distraction is enormous to the extent that we get lost to a magnitude of ending up buying something else rather than what we were supposed to at the first place. I believe in the trend to be a contrarian means to explore different kinds of shoes

Further outside the creation of design, fast growing corporations are shaping a new method to creating and building their character. Swift, the online shoe retailer that pleasures itself on its customer service, and is keen to give away surprises to anyone who cares to listen. Previously with a boom in e-commerce the idea of selling shoes online was not much cherished. Not a lot of customers wanted to buy shoes online as it was hard to search a perfect pair and there were difficulties of returning shoes through mail. As an "innovator and visionary", Swift is giving individuality and flair to online service.

Stepping outside the design industry, there are many examples of brands that make distinctive and gripping identities that push their industry model on much greater heights. In a world that has expanded with data over the past two decades, it wouldn't be surprising that companies are no longer threatened by their rivals who will find out their secret of success. The days are fading when such secrets would be concealed. Swift leads the online shoe selling with models including play and enjoyment that can draw major attention for our clients and competitors alike.

\section{OBJECTIVE}

Swift is single task fulfillment platform, augmented with easy to use mobile applications (Android /iOS mobile application which aims at:

- Testing this new trend with Buy and sell shoes

- Understanding user behavior and needs

- Providing the best user experience ever.

With a strong inclination towards succeeding and developing this product to give the best customers satisfaction we believe we have what it takes to face the challenges and rigor to test this product. Swift would be an ideal step in our career path which will eventually lead to us to using the best management practices coupled with engineering techniques to lead Swift trying to solve the chaos and distraction by churning brilliant minds to spurn extraordinary results. We are certain that the resulting synergy will not be unilateral.

Karthikeyan Chinnusamy, International Technological University (ITU), USA. (e-mail: karthikchinnusamy@ieee.org)

Naresh Reddy Malgireddy, International Technological University (ITU), USA. (e-mail: naresh.malgireddy@gspann.com). 


\section{SCOPE}

The scope of the product is enormous. Swift can be accessed on both Android and IOS.

- Available on Android \& iOS:

- Signup and Login into the application: Once you sign up, you'll land on the log in page

- Single Sign-on Authentication using Facebook or Gmail Id or Twitter account

- Enter your style and specifications: You can customize your shoes with wide variety of patterns and color

- Suggest similar variety based on specification

- Create \& View your own style studio. You can try it out on yourself by using the style studio feature. It's a simple drag and drop process on your image inside the app.

- Analyze the Feedback by other customers who have previously brought the shoes

- Finally, place the order which is ready to ship / delivery

\section{COMPETING LANDSCAPE}

You can't argue with success, but you can learn from it. And companies everywhere are learning from and emulating Swift. After performing market analysis on our project, companies that might Swift's main competitor are as follows.

1. Zappos

2. Footlocker

3. JC Penny

4. Just Fab

5. Amazon

6. EBay

Statistical analysis shows us that total US footwear industry industry is about 63 billion of revenue every year.

The market grows by $+3 \%$ every year which ideally is about 2 billion in number just through incremental sales.

Our strategy is built on teamwork and getting to know and understand our client's business. We practice a step by step method to bring a store and warehouse from a brand placement to a retail experience.

The high light of our strategy is to customize the needs and requirements of the customer on the shoes using our app.

\section{SWOT}

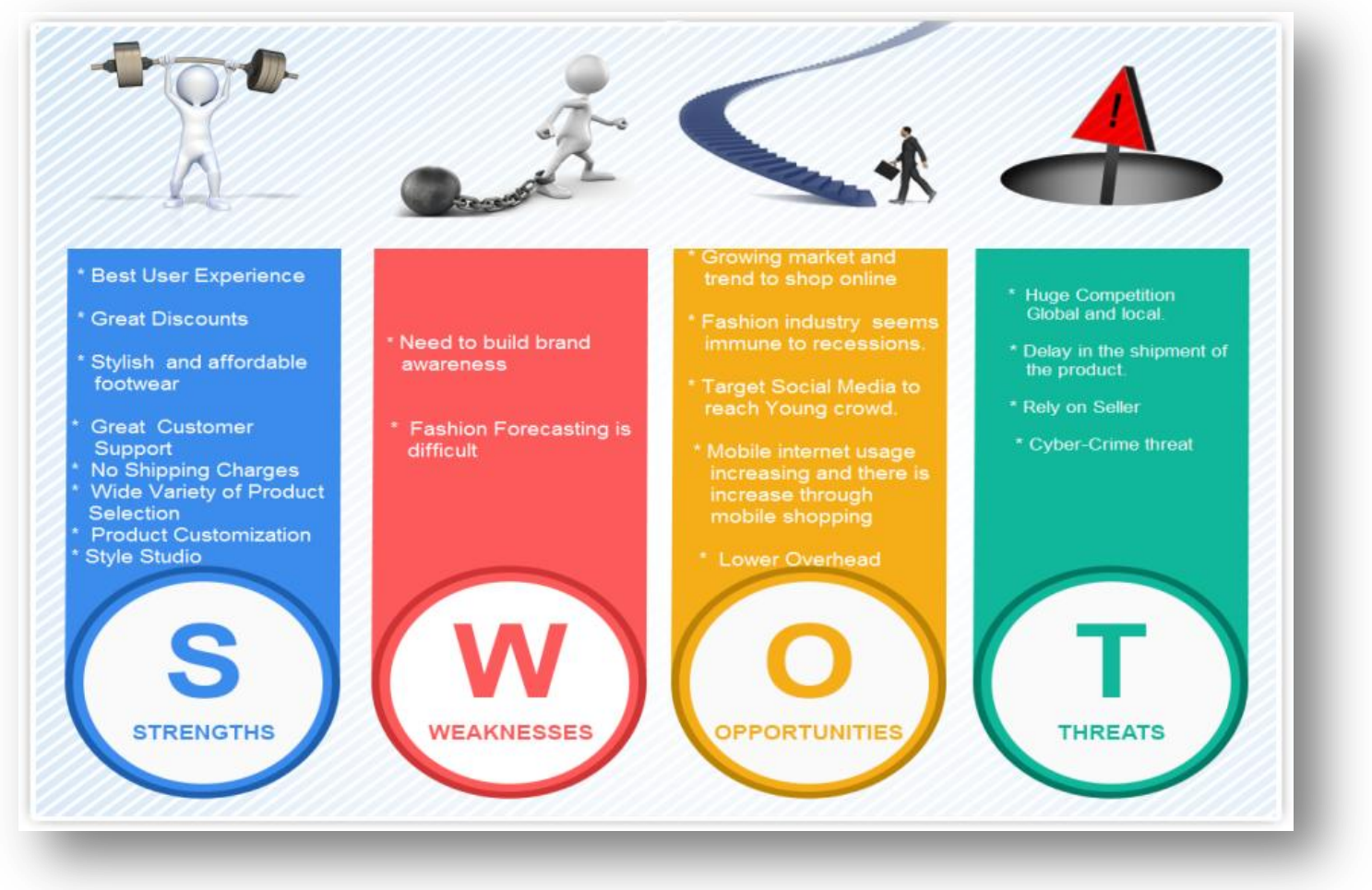

\section{Strength}

Swift does not have a brick-and-mortar store and their business is conducted online only which eliminates the problem of limited sizes and inventory. The Swift mobile app allows the customer to quickly find exactly what they are looking for in different styles or sizes. Swift offers Stylish and affordable footwear with a reasonable price due to the fact that the product comes straight from the manufacturer, through us, to the consumer. Cost efficiency and customer service play a key role in this organization. We too have a strong and dedicated team for support and offers great discount to our new and existing customers.
Style Studio feature also enables customers to mix and match shoes and create the desired look on his/her image before making a purchase decision.

\section{Weakness}

We are a new comer in the E-Retail Commerce business and the competition is rough. It is not easy for a small startup company to compete with already existing giant companies.

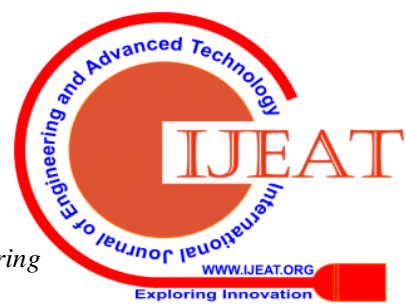


We have to break our selves through in order to penetrate this market. Also we need to create a tight bond between our suppliers, and customers for a long-term relationship and good deals.

\section{Opportunities}

We have a good opportunity to grow as a company in this fairly new market. As an online store the possibilities to expand are endless. We also have chances to make big sales and profits in this environment. In addition, the economical situation is getting better all the time and it also shows on the consumer behavior. Online shopping is also rising among consumer, which gives us a head start to the trend in this business. Fashion industry is an industry which seems to be immune to recession.

\section{Threats}

The competition of other Online Shore stores is always a threat. Competitors already have a stable position in this market and that is why breaking our selves through, is not going to be that easy. Also there is always the threat of new entering companies to the market. There are some other threat of losing a customer due to delay in shipment of a product. Also, knowing the buying trend of your customer is another challenge that needs to be assesses before. Additionally, with the rise of cyber-crimes and hacking, online retailers are at a higher risk of security breaches.

\section{FIVE FORCE MODEL}

Threat of

New

Entrants

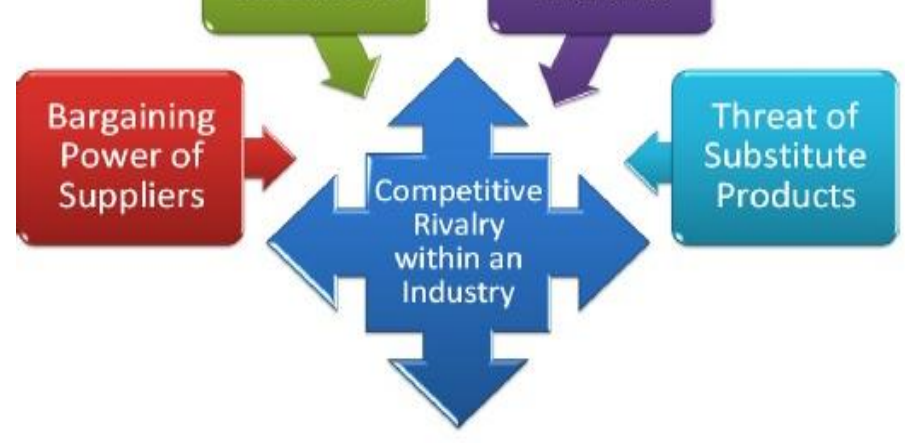

Porter's five forces analysis is a framework for industry analysis and business strategy development which draws upon industrial organization economics to derive five forces that determine the competitive intensity and therefore attractiveness of a market. They consist of those forces close to a company that affect its ability to serve its customers and make a profit. A change in any of the forces normally requires a business unit to re-assess the market place given the overall change in industry information.

Threat of New Competition: In the Online Retailing industry the barriers to entry/exit and setup capital and working capital are low therefore, the threat of a new entrant becomes high.

Threat of substitute services:Online retailing can be considered to be a substitute to the usual shop retailing. FootStep cannot provide the customer with a real retailing experience but at the same time gives the convenience of shopping from home/office. But with the increase in the tendency of shopping online this threat becomes low priority.

Bargaining Power of Customers: The bargaining power of customers is also described as the market of outputs: the ability of customers to put the firm under pressure, which also affects the customer's sensitivity to price changes. retailer; this puts pressure on the company to continuously improvise on their service so as to keep their users satisfied. Also with so many big e- retailers in the market it becomes tough to compete. Therefore bargaining power of customers threat becomes high priority. Customers can very easily switch to some other online

Bargaining Power of Suppliers: The suppliers in this case are the various brands whose products are being sold by the company. They can demand an increase in their profit margin and put pressure on the company. The supplier may choose a competitor of the firm to do business since the supplier switching costs are low. Therefore the bargaining power of suppliers is high and FootStep needs to have good supplier relations priority.

Intensity of competitive rivalry: As already mentioned there are $n$ numbers of big and small players in the market. Therefore this threat becomes the high priority.

\section{BUSINESS MODEL\& CONCEPT OF SWIFT}

Our business model is simple. It involves just the buyer and seller who can interact through a single platform SWIFT for purchasing and selling SHOES. We wish to deliver products extremely fast and provide the best user experience and customer service possible.

The model here is : App > List Sellers who sell the various footwear's from the list of products $>$ Get customers to view the products > Customer Shops for the desired products $>$ products shipped to the customer $>$ Product Accepted $>$ Seller gets his agreed price of the product minus the commission charged by Swift after a specified period of the time.

Thus the core bread and butter of the Model is " $\mathrm{X} \%$ commission on the total sale value given to the seller". 


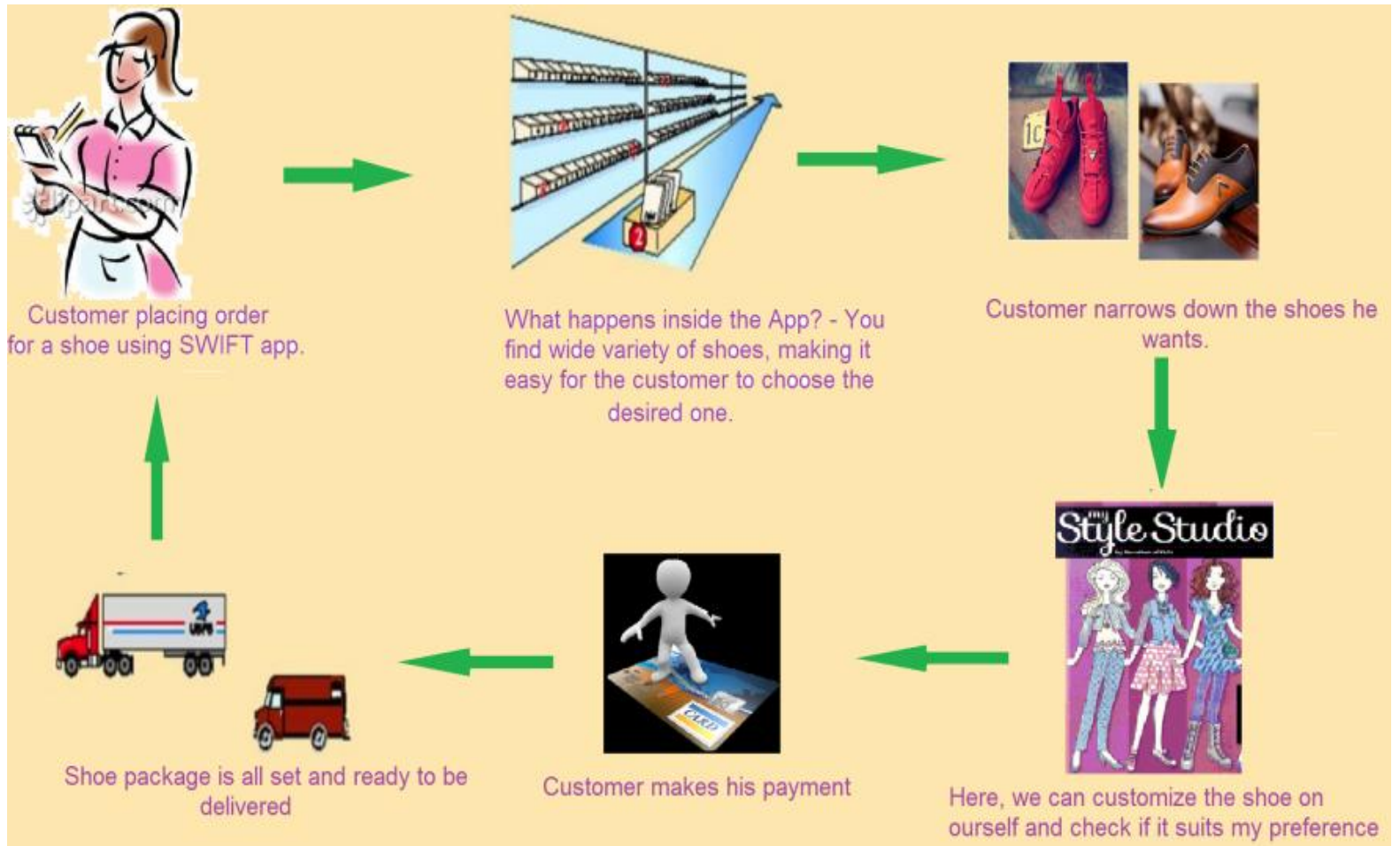

\section{Style Studio}

Style studio is a virtual dressing room to make online shopping fun and interactive for shoppers. Through this style studio, customers are able to click pictures of themselves using web-camera, click on a product they want to try and see how it looks on them before making a purchase decision. The objective of this feature is to guide the user through their purchase experience and enable them to virtually try before they buy.

\section{USE CASES}

UC- 01 Register/SingIn flow

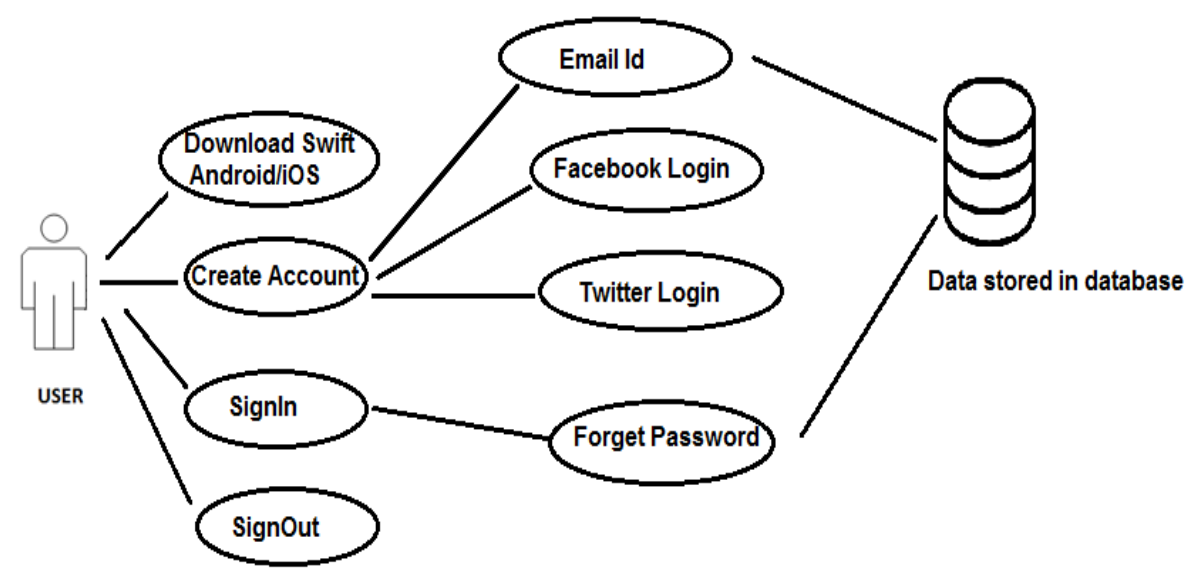

Register/SignIn Use Case

Use case Name: Register and signIn

Objective: This use case describes the activities associated with a user when he/she downloads the app on android or IOS platform and creates his/her account on SWIFT to shop shoes Online.A CUSTOMER needs to login before performing any transaction

\section{Actors}

1. SWIFT App User - the application user Pre-condition: A registered user.

\section{Flow of Events}

1. Download the app: User will install the app on the phone from playstore or app store

2. Create Account: First time user will create an account on SWIFT by entering Email Id or through Facebook and Twitter account. The system displays the Register Page. The CUSTOMER enters all of the required information.

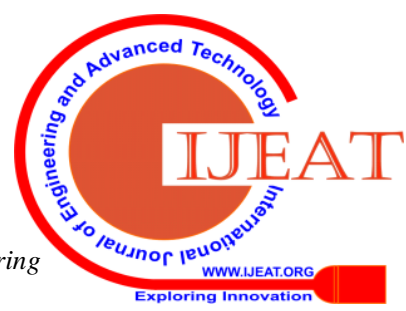


3. The CUSTOMER clicks the SEND button. 5. The system checks that all of the required information were entered. If yes, the system update the CUSTOMER's record in the CUSTOMER and ACCOUNT tables in the database. System displays OK message.

4. User login - User will be able to login the SWIFT app by entering user id/ password.
5. User Validation - User credentials will be validated by the System.

6. Show user Own/Account page - User can see view activities associated with his/her account.

7. Sign-out - User will be able to sign-out from the app UC-02 Product Purchase flow

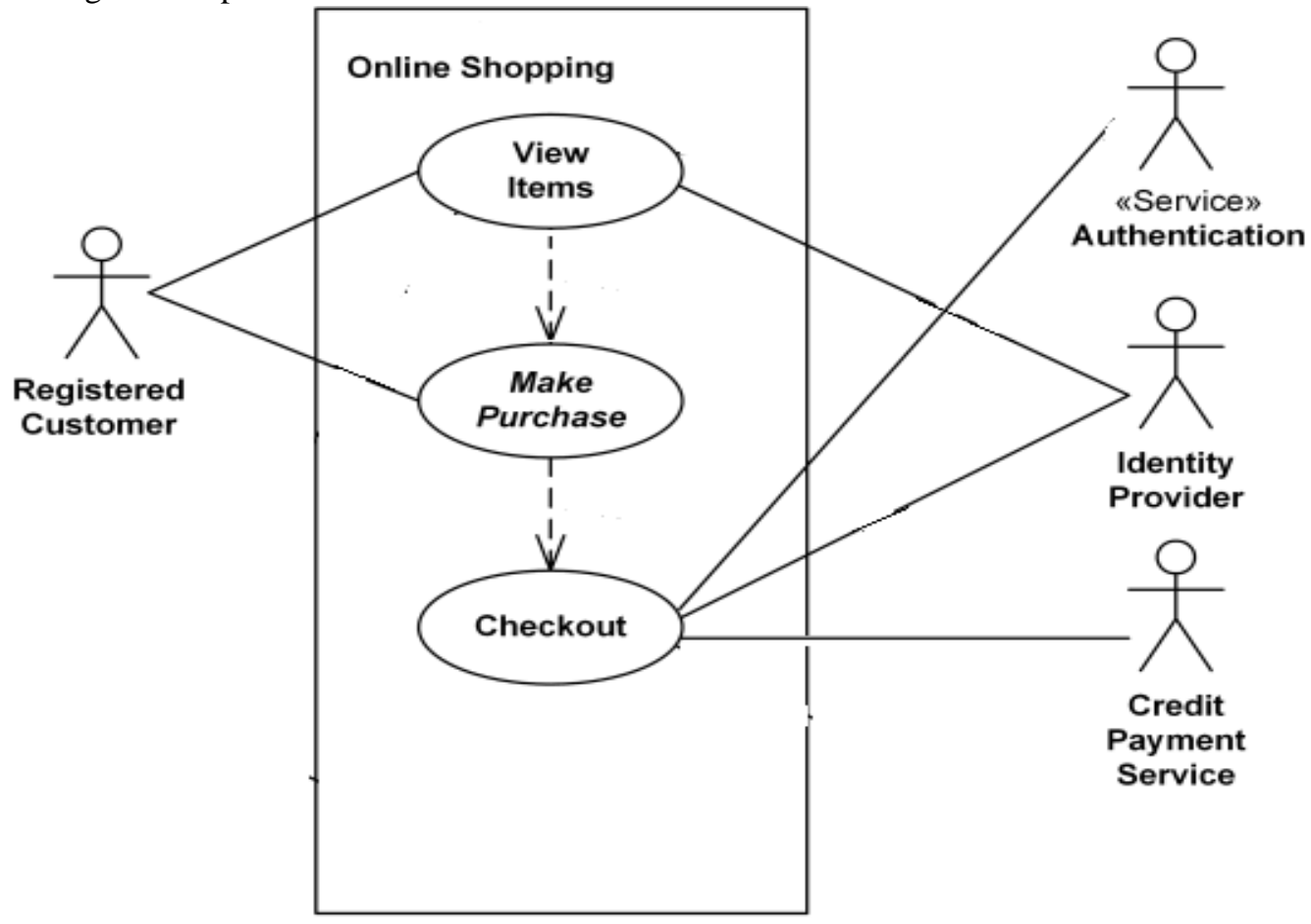

Use case Name: SWIFT User Purchase flow activity:

Objective: This use case describes the activities associated with a user when logins to the SWIFT app and selects the shoes and makes purchase.

\section{Actors}

1. SWIFT App User - the application user

Flow of Events

1. User enters specification - User will login to the SWIFT app and then submit the shoes specifications.

2. View Items - User can view different shoe options sorted after defining the specifications.

3. Make Purchase - User after finalizing the shoes is directed towards the payment gateway.

4. Checkout- Checkout use case includes several required uses cases. Web customer should be authenticated. It could be done through user login page, user authentication cookie ("Remember me") or Single Sign-On (SSO).Checkout use case also includes Payment use case which could be done either by using credit card and external credit payment service or with PayPal.

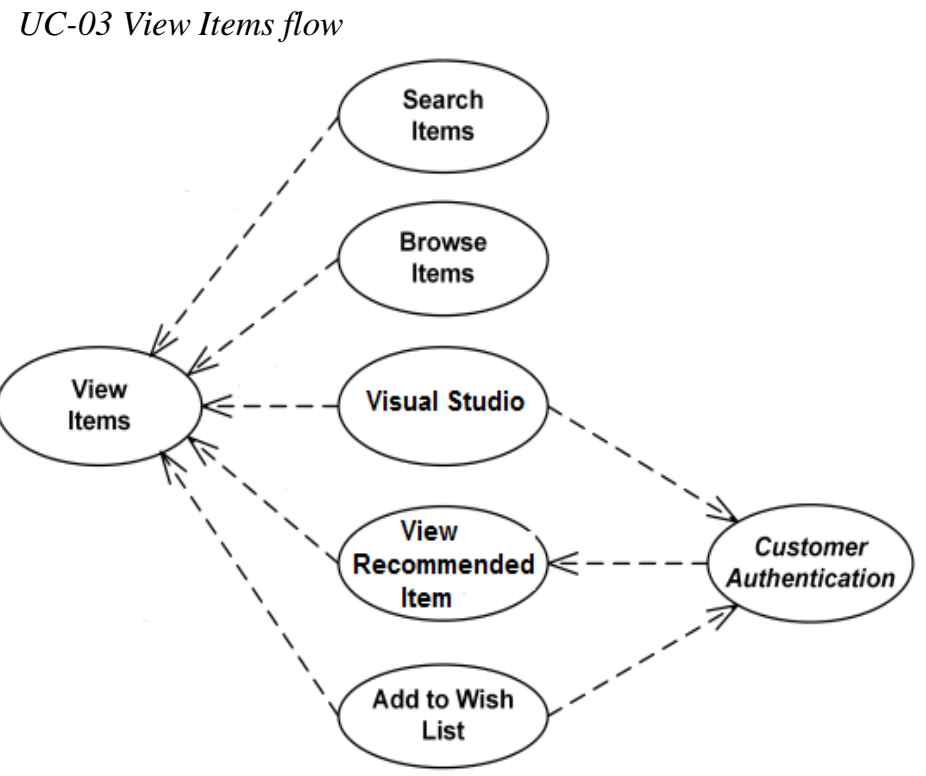

Use case Name: View Item flow activity:

Objective: This use case describes the activities associated with a user when user add the shoe specifications and browse for the items.

\section{Actors}

1. SWIFT App User - the application user 


\section{Flow of Events}

1. View Items use case is extended by several optional use cases - customer may search for shoes, browse shoes view shoes recommended for him/her, add shoes to shopping cart or wish list. All these use cases are extending use cases because they provide some optional functions allowing customer to find item.

2. Selected shoes user can check on style studio how it would look. Through style studio user can take his/her image and scroll selected shoes and check how it will look like.

3. Customer Authentication use case is included in View Recommended Items and Add to Wish List because both require the customer to be authenticated. At the same time, item could be added to the shopping cart without user authentication.

\section{AGILE METHODOLOGY \& ROADMAP}

\section{Road map}

Our platform is mainly based on mobile since that's the most widely used device for making online purchases. Our goal is to start development of the app beginning January 2017. And move to enhance phase by July 2017. Our planned configuration for development during the timeline is as follows:

\section{Front-end}

We plan to implement front end languages such as Angular, HTML5, CSS3, bootstrap and build advance web components and modern user interface for our customers.

We would periodically look for scope for improvement and take constant feedback from designers and customers to improve the interface and make user experience better.

\section{Back-end}

Since Amazon AWS can help us build sophisticated applications with increased flexibility, scalability and reliability. We will be using that for compute power, database storage, content delivery or other related functionality.

The JavaServer Pages Standard Tag Library (JSTL) encapsulates as simple tags the core functionality common to many Web applications. JSTL has support for common, structural tasks such as iteration and conditionals, tags for manipulating XML documents, internationalization tags, and SQL tags.

\section{API}

Representational State Transfer (REST) which is an architectural style that specifies constraints would be applied to our web service will get us desirable properties, such as performance, scalability, and modifiability, that enable services to work best on the Web.

Security

We plan to implement token authentication for users who login through their account/ social profiles. A unique key will be generated as the used tries to $\log$ in and the unique number will be matched based on user credentials.

\section{Database}

SQLite is the most widely used in-process library that implements a self-contained, serverless, zero-configuration, transactional SQL database engine. SQLite is an embedded SQL database engine. Our appwill beavailable on IOS and as well as android.

\section{Value Proposition}

Online shoe shopping is undoubtedly on an upward trajectory. But, here's the kicker: While $43 \%$ of sales are influenced by online, online sales account for only about $9 \%$ of retail. It's still an impressive figure, but it also shows that there's huge room for improvement. There are still groups of online shoppers who refuse to buy online - and your great products, competitive prices, or easy check out have little to do with it.It's a common perception that having a large variety of products is key to online domination. However, psychology experts suggest that choosing between a large number of products can be physically tiring. Offering too many selections without any choosing support is a source of great consumer frustration that you have to be mindful of. Once your shoppers are stressed out, there's every chance that they won't choose anything at all.It's crucial to always consider the mind and purchase path of your customer. Many consumers, especially millennial, shop online not knowing what they want exactly, but they know they want it fast. Swift is a passionate and knowledgeable expert app that helps them discover shoes they'll love and offers them ways to easily and intuitively pick the product that's right for them.

Humans are tactile beings and sensory experiences are a fundamental part of their shopping experience. Not being able to physically try out and touch a product is probably one of the biggest cons of online shopping. To make up for this disadvantage, Swift goes the extra mile and sell the online shoe experience and not just a product. Swift persuades shoppers with compelling product descriptions that highlight the benefits of each feature and appeal to their imagination. The app contains in-depth product descriptions that goes beyond telling shoppers what the product is and instead explain why it's great for them. Details includes how the product feels, how it helps them solve a problem, save time, or how it makes them happier. Along with complementary photos, graphics and videos. It's about entertaining the customers as why shoe shopping experience can be enjoyable rather than just to inform them.

Swift has rich, enjoyable adventures that resonate with today's impatient shoppers. Integrating approaches and technologies that make shopping more interactive and engaging, such as: Swift app provides a search functionality where customers can filter the shoe of their taste and style. Additionally, Swift has a feature called 'Make a request' feature which provides people to click/upload pictures of shoes they like, describe in few word about the specifics and send a request through the app. Based on the data, the app uses algorithm to provide the closest search results to the customers along with network search with the retail partners and third party vendors.

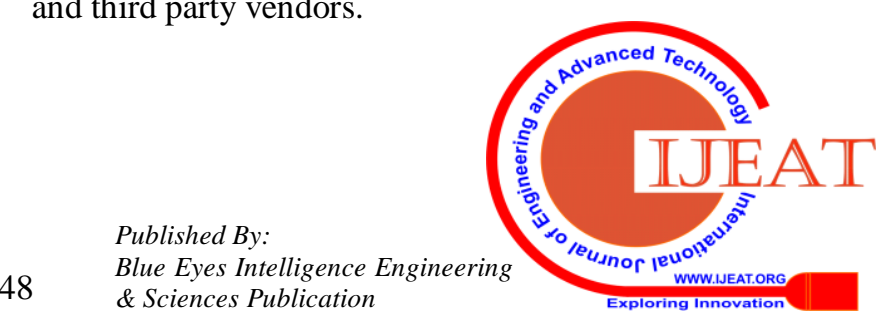


If the retail store has something similar to the information provided, the customers are notified through email within two days.

The app also has another interesting feature called 'Visual studio'. Customers often want to purchase products that goes well with their clothes. Since we want consumer to feel as if they entered a real store, they can select the shoes of their taste and align with their personal photos to get a visual idea. Swift goes that extra mile for the customers and addresses their inconvenient online shopping experience to pay off in one way or another. We believe conversions happens when we get the basics right and go beyond simply putting products out on display.

\section{WIREFRAMES AND SCREENSHOTS \& RESULTS}

When it comes to every day chores, you might think that things are pretty simple. Well, think again. Sure, going to the store is easy enough, but what happens if they just don't have that shoe you like? Digital shopping has soared in recent years, stamping out the drudgery and inconvenience of in-store browsing. But that means that the sites that we buy from need to be quick and easy to use.Swift goes a step beyond customization in that it doesn't just touch the way things look to users, it also is the way things feel to users. It delivers the content users want it, based on their past use, their preferences. So, say a user exhibits interest in content related to specific to their taste. When that user launches the Swift app, the content will alternate in delivering results tied to those taste. This is paramount in creating a user experience that is bothunified and pleasing.

One of the best things about online shopping is not having to wait in line behind a long line of equally frustrated shoppers at the cash register. You have your very own cashier every single time you decide to $\log$ on to your favorite ecommerce site and indulge in some retail therapy.
User login

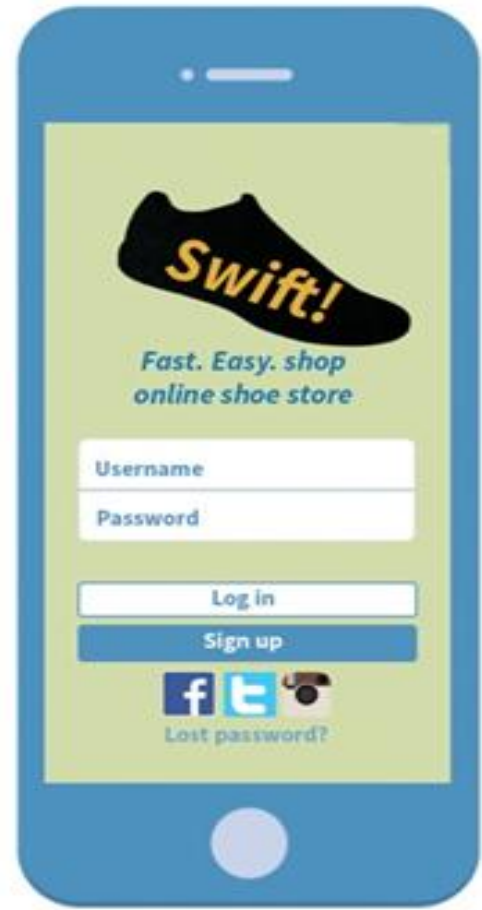

Above image is the main login page, where the user can sign in into Swift account by using username/password. A customer can also login through their social profile to make theirs sign up process less time consuming. The app collects the login details, creates a token for authentication and gives the user access to the landing page. The landing page comes with a simple search box and view options for user's preference of navigating search results. The search engine is programmed according to the relevance of the word search and additionally lists a type-ahead dropdown. As Search Engine Optimization grows more and more complex, it starts to lose meaning in its name. It will no longer be about optimizing the app for the sake of search engines. It's morphing into something new, akin to content optimization for the User.In order to make a great e-commerce checkout flow, we follow strict guidelines to make the experience better:

- Improve page load time. anding page

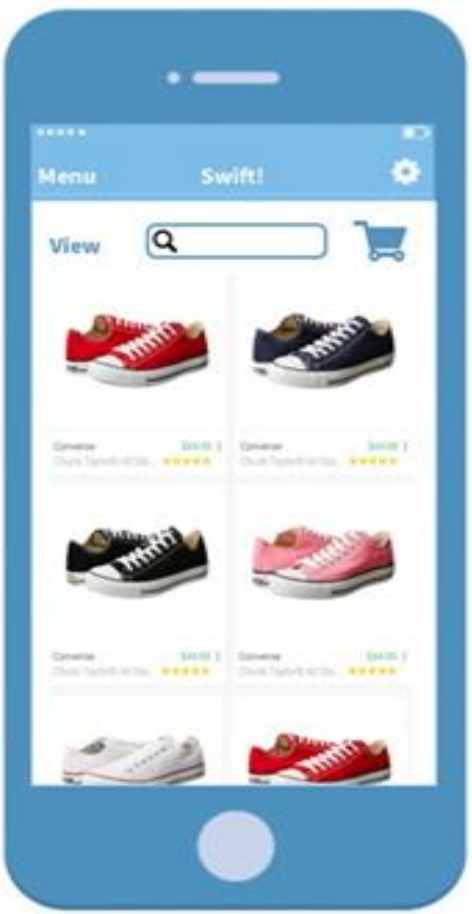

- Make your pages accessible on all mobile devices.

- Don't get people to bounce off/exit your checkout page.

- Deliver a clean user interface.

- Implement a simple and properly formatted URL structure.

- Adopt the HTTPs protocol.

- Use linear steps in your ecommerce checkout flow.

In doing a great SEO job, we'll also be providing your customers with a great checkout flow experience. That means we start with a powerful base from Search Engine Optimization and automatically do fantastic in moving our users towards the thank-you page. The user gets the option to make multiple selection and add to cart and the second page shows the list of items selected for review.

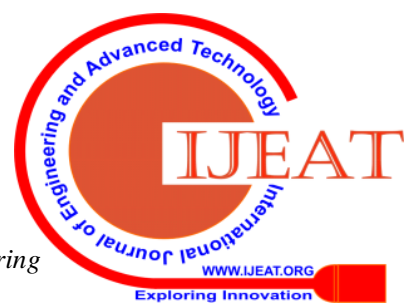


The item selected page, contains detailed information of the shoe along with size and color selection options. We provide comprehensive feedback page for customer reviews and ratings and group the top reviews for customers who would like to sort helpful comments. The goal with all of these improvements is to be able to provide customers with a one-minute checkout process. As our attention span online keeps dropping (it's now at a record low 8.25 seconds), it is our duty to understand the world around us and make it easier for our customers to make a purchase on the online. We want to help our users get to the thank-you page faster by increasing website load speed.

We provide special features such as 'Make a request' which you can find in the main menu. Selecting this feature is available on all pages which will get you to the feature page. Customers sometimes struggle to find the shoes of their taste online and even with advance search engines, they don't get the desired results. It provides you the option of displaying pictures of shoes you took outdoors but you couldn't find it on online stores. You can pick pictures from your photo album or upload pictures, group them together and describe in the text area below about the specifics you are looking for. Hitting the request button will submit your details to us. Our app will run the algorithm based on the details collected and give you the best search results online. Additionally, our Swift team will pass your details to check with our partner stores and distributors for the requested item. We notify the customer within two days if we found the items they were looking for or provide close recommendations.

\section{Make a request}

Menu page

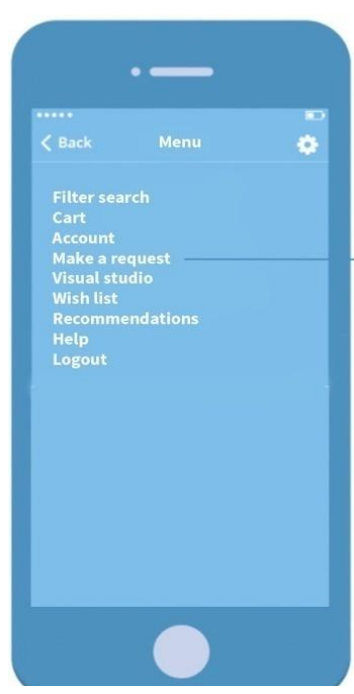

rizontally from the album
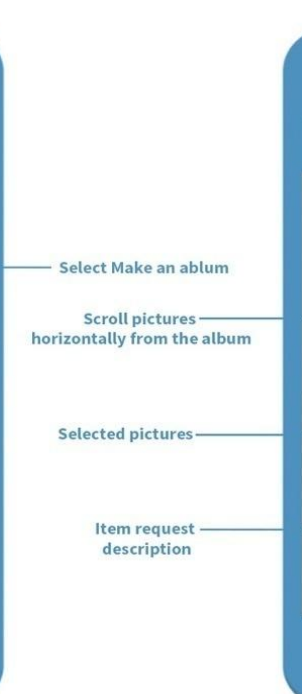

Product request page

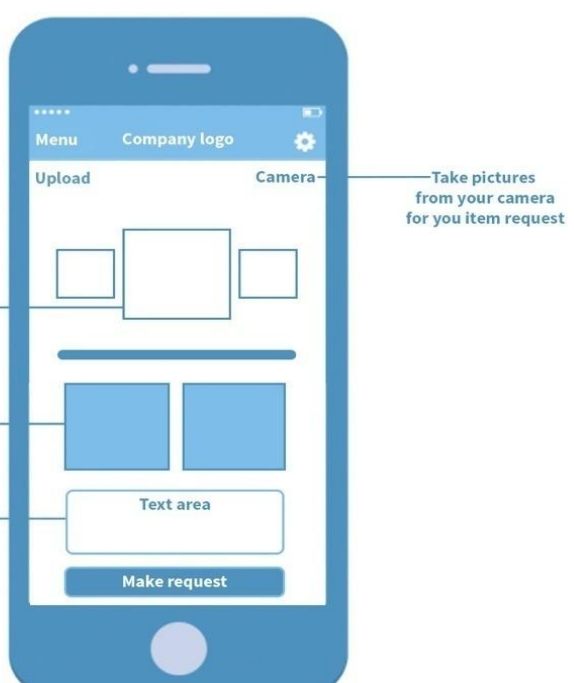

Result page

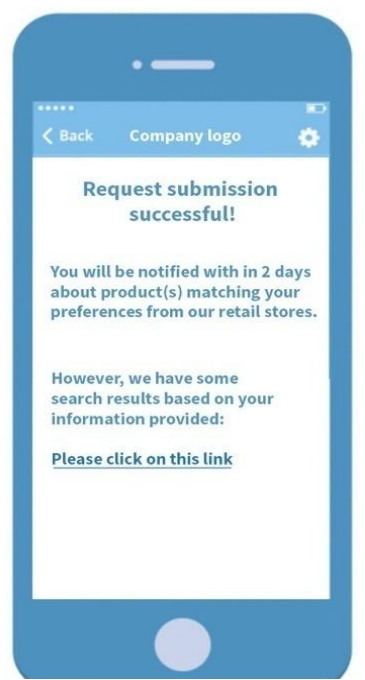

Another important feature of our app worth noting is the Visual Studio.

Visual Studio

Menu page

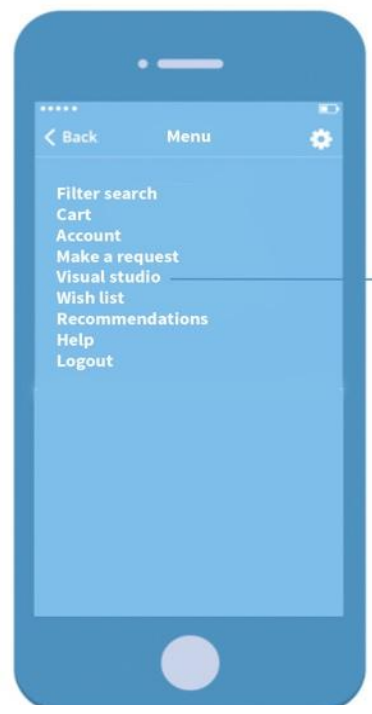

Visual studio which is also located in our main menu gives you the visual perspective of how the shoes would fit with your clothing. The aim is to make customers feel as if
Result page

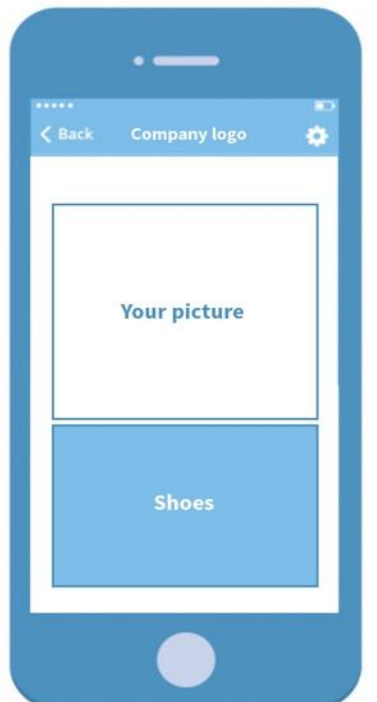

they entered a physical store and give them the satisfaction by seeing how well the shoe fits with their clothes. 
You can pull out pictures of yourself from your album and match it with the shoes you selected in our app. Once you hit the Match button, the app navigates you to the zoomed version of the result. We also offer a 360 view option if you took a panoramic view of yourself. You can rotate the picture which provides you wider range of seeing yourself visually wearing the item selected. We plan our mobile app personalization with the user in mind that will help our users realize the most ultimate mobile user experience and bring them back to our app.

\section{FINANCIAL ANALYSIS}

Every product has its own cost. The product that fits in with the best cost along with the best available resources will play a huge impact in determining the financial model of that product. Based on the needs and requirement of SWIFT we performed an in-depth financial analysis and the questions that lingered in our mind are as follows:

What is the overall cost to launch the product in the market.

No of the developers required to complete the project

How are we going to perform market campaign based on our budget.

And we zeroed in on the following answers for the above question.

The total budget from start to release the product in the market required is $\$ 500,000$. This can be classified under the following categories:

A. $\$ 100 \mathrm{~K} /$ Annually - Android app development

B. $\$ 100 \mathrm{~K} /$ Annually - iOS app development

C. $\$ 100 \mathrm{~K} /$ Annually - Full Stack Developer

D. $\$ 150 \mathrm{~K} /$ Annually- For our team (Product Manager \& Marketing Lead)

E. $\$ 50 \mathrm{~K} /$ Annually- Other Expenses

\section{CONCLUSION}

Swift mobile app will provide rich online shopping experience for the customer by providing the right products. With the help of the mentioned solutions, you can get your website optimized and help visitors overcome these online shopping challenges to boost your ecommerce sales. Customer can Create \& View their own style and try it out on them by using the style studio feature. $81 \%$ of customers say that they will buy from a platform again if they were satisfied with the experience. Hence, going that extra mile for our customers and addressing their pain points will surely pay off in future. Remember, putting products on the display is not enough, conversions happen when everything goes well till end.

\section{REFERENCES}

1. 10 Little-Known Ways to See How Much Traffic a Website Gets - How To Make Money Online. Retrieved December 17, 2016, from http://www.incomediary.com/how-much-trafficwebsite-gets

2. Bloomberg.com/news/articles/2010-05-27/tonyhsieh-redefining-zappos-business-model

3. Source: The NPD Group/Consumer Tracking Service, 12ME Apr" 15
4. Fakhroutdinov, K. (n.d.). UML Diagram Examples Online Shopping. Retrieved December 17, 2016, from http://www.umldiagrams.org/examples/online-shoppingexample.html

5. Online Retail Business: How to Start an Online Business. Retrieved December 17, 2016, from http://ecommerce-platforms.com/ecommerceselling-advice/10-easy-steps-to-establishing-anonline-retail-store 